\title{
General Psychiatry Prevalence of excessive internet use and its correlation with associated psychopathology in 11th and 12th grade students
}

\author{
Nitin Kumar, ${ }^{1}$ Arvind Kumar, ${ }^{1}$ Subodh Kumar Mahto, ${ }^{2}$ Manish Kandpal, ${ }^{1}$ \\ Smita Neelkanth Deshpande, ${ }^{1}$ Parul Tanwar ${ }^{3}$
}

To cite: Kumar N, Kumar A, Mahto SK, et al. Prevalence of excessive internet use and its correlation with associated psychopathology in 11th and 12th grade students. General Psychiatry 2019;32:e100001. doi:10.1136/ gpsych-2018-100001

Received 10 August 2018 Revised 10 December 2018 Accepted 07 January 2019

Check for updates

(c) Author(s) (or their employer(s)) 2019. Re-use permitted under CC BY-NC. No commercial re-use. See rights and permissions. Published by BMJ.

${ }^{1}$ Department of Psychiatry, Dr Ram Manohar Lohia Hospital and Post Graduate Institute of Medical Education and Research, New Delhi, India ${ }^{2}$ Department of Medicine, Dr Ram Manohar Lohia Hospital and Post Graduate Institute of Medical Education and Research, New Delhi, India ${ }^{3}$ Vardhman Mahavir Medical College and Safdarjung Hospital, New Delhi, India

Correspondence to Dr Nitin Kumar; drnitinkumarvmmc@gmail.com

Dr Manish Kandpal; drmanishkandpal@yahoo.com

\section{ABSTRACT}

Background Globally, the number of internet users has crossed the three-billion mark, while in India users grew over $17 \%$ in the first 6 months of 2015 to 354 million. This study presented a background on internet use and the existence of excessive internet use.

Aim To study the extent of internet use in 11th and 12 grade students and the psychopathology, if any, associated with excessive internet use.

Methods 426 students who met the inclusion criteria were recruited from 11th and 12th grade classes from Kendriya Vidyalaya, New Delhi, India, and were assessed by Young's Internet Addiction Test and the Strength and Difficulties Questionnaire.

Results Among the 426 students, the mean internet addiction total score was 36.63 (20.78), which indicated mild level of internet addiction. 1.41\% (six students) was diagnosed as excessive internet users, while $30.28 \%$ and $23.94 \%$ were classified as moderate and mild internet users, respectively. The prevalence of internet addiction between gender was $58.22 \%$ in males and $41.78 \%$ in females. While both positive (prosocial) and negative (hyperactivity, emotional, conduct and peer problem) impacts of internet use were reported by students, in the current study excessive use of internet had a negative impact on students' lives as compared with positive impact, which was statistically significant $(p<0.0001)$. Conclusion Excessive internet use led to abnormal behaviours which cause negative consequences to users. Early diagnosis of risk factors related to excessive internet use, provides education about responsible use and supervision of students by family members.

\section{INTRODUCTION}

In 2017, global internet users were $48.7 \%$ in Asia, $17 \%$ in Europe and $10.9 \%$ in Africa (Internet World Stats, 2017). Due to the development and spread of cheaper and more user-friendly computer technology and software (eg, portable computers, Microsoft Word), the use of the internet has increased dramatically. The penetration of the internet increased from $0.5 \%$ of the population in 2000 to $34.1 \%$ in $2017 .^{1}$ Due to the popularity of the internet and the issue on the negative impact of its use, internet addiction (IA) has received critical consideration.

Many studies are still ongoing on the concept and the definitions of Internet addiction in the literature, controversy around suggested diagnostic criteria, and whether IA truly exists as a diagnosable addiction or not. Indeed, most IA theorists have based their definitions of IA on established addiction conceptual frameworks; for example, IA has been recognised as a potential problem since the introduction of the term by Ivan Goldberg in $1996 .{ }^{2}$ Davis $^{3}$ preferred the term 'Pathological Internet Use (PIU)' instead of IA as it resembles psychoactive substances dependency, and is defined as an inability to control internet use and leads to psychological, social, family, school and work impairment.

Young ${ }^{4}$ linked excessive internet use to pathological gambling disorder under the Diagnostic and Statistical Manual-IV (DSM) and modified it to make diagnostic criteria for 'problematic internet use'. Previous self-report surveys indicated the prevalence rate of IA among adolescents ranges from $0.9 \%$ to $38 \% .^{5}$ Excessive internet use, as defined by Ran Tao and colleagues, ${ }^{6}$ is considered as an impulse-control disorder that includes salience, mood modification, tolerance, withdrawal symptoms, conflict and relapse. The eight IA disorder symptoms are (1) preoccupation with the internet, (2) withdrawal symptoms, (3) tolerance, (4) unsuccessful attempts to control internet use, (5) continued excessive internet use despite knowledge of negative psychosocial problems, (6) loss of interests, previous hobbies and entertainment as a result of internet use, (7) use of the internet to escape or relieve dysphonic mood, and (8) deception of family members, therapists or others. Many 
epidemiological studies done on students from schools in various countries have found the prevalence rates of IA from a low of $1 \%$ in Greece ${ }^{7}$ to a high of $36.7 \%$ in Italy. ${ }^{8}$ IA has also drawn attention from health professionals, educators and the public as this phenomenon has been found to result in negative consequences for IA sufferers. School children are the most vulnerable to internet use due to the following factors: ease of use, availability of time, limited parental supervision, route of escape and social interaction. ${ }^{9}$ Excessive internet use is associated with attention-deficit/hyperactivity disorder, ${ }^{10}$ depressive symptoms, ${ }^{11}$ anxiety disorder,${ }^{12}$ low self-esteem, ${ }^{13}$ shyness, ${ }^{14}$ social anxiety ${ }^{15}$ and suicidal ideas. ${ }^{16}{ }^{17}$ IA is not recognised by the DSM-V as a disorder, but it is considered as an area of further research. ${ }^{18}$ A number of studies have been conducted worldwide but used inconsistent criteria to check the level of addiction. The main use of the internet for students is interpersonal communication through email, instant messaging and chat programs. ${ }^{19}$ This study presented a background on the internet and how this has expanded in use and has led to the existence of IA.

Previous Indian researches have not conducted studies on school students to find out prevalence of internet use and its effect on them. Our study found out that excessive Internet use led to the abnormal behavior which causes negative consequences to its users. Early diagnosis of risk factor related to excessive internet use, provide education about responsible use and supervision of students by family members.

\section{METHODS}

This cross-sectional study was carried out in 426 students of senior secondary school of 11th and 12th grade classes from Kendriya Vidyalaya, and conducted by the Department of Psychiatry, from 1 November 2016 to 31 March 2017. Participants who were willing to give assent and with their parents giving consent through a parent-teacher meeting were included. Permission from the school board was taken to conduct the research, and assenting students were assessed by Young's Internet Addiction Test $(\mathrm{IAT})^{20}$ and the Strength and Difficulties Questionnaire $(\mathrm{SDQ})^{21}$ (figure 1).

The IAT was developed by Young $(1998)^{4}$ to measure the presence and severity of IA. The IAT measures self-reported compulsive use of the internet and assesses symptoms of IA. The test includes 20 items, with each item rated on a 5-point Likert scale ranging from 0 to 5 , with the maximum score being 100 . The IAT has the following ranges of scores:

1. A total score of 0-30 points indicates normal internet usage.

2. A total score of 31-49 indicates mild level of IA.

3. A total score of 50-79 indicates moderate level of IA.

4. A total score of 80-100 indicates excessive internet use.

The associated psychopathology of the same group of students was assessed using the SDQ.

The SDQ is a mental health screening tool used among children and adolescents aged about 2 to 17 years old. It exists in several versions to meet the needs of researchers, clinicians and educationalists. Each version includes 25 items on psychological attributes.

Figure 1 Flowchart of the study. 
Table 1 Frequency distribution of demographic variables

\begin{tabular}{lll}
\hline Baseline variables & Frequency $(\mathbf{N}=\mathbf{4 2 6})$ & Percentage \\
\hline Sex & & \\
$\quad$ Male & 248 & 58.22 \\
\hline Female & 170 & 41.78 \\
Grade & & \\
$\quad 11$ th & 246 & 57.75 \\
\hline 12th & 180 & 42.25 \\
Stream & & \\
$\quad$ Humanities & 151 & 35.54 \\
$\quad$ Commerce & 135 & 31.69 \\
\hline Science & 140 & 32.86 \\
\hline
\end{tabular}

All versions of the SDQ ask about 25 attributes, some positive and others negative. These 25 items are divided among five scales: emotional symptoms (five items), conduct problems (five items), hyperactivity/inattention (five items), peer relationship problems (five items) and prosocial behaviours (five items).

Students were asked to respond to a Likert scale with the following responses-not true, somewhat true and certainly true-and then four band categorisations of SDQ scores were done as follows:

1. close to average category;

2. slightly raised;

3. high;

4. very high category.

\section{Statistical analysis}

Data were entered in MS Excel spreadsheet and analysis was done using Statistical Package for Social Sciences (SPSS) V.21.0. To compare qualitative variables among groups, $\chi^{2}$ test was used. For quantitative variables, t-test was used to compare the means between two independent groups with normal distribution. Spearman rank correlation coefficient and Kruskal-Wallis test were used. For all analyses, the level of significance was set at $p<0.05$.

\section{RESULTS}

A total of 426 students were enrolled in this study and assessed by the IAT and SDQ scales. Among the enrolled 426 participants, there were $58.22 \%$ males (248) and
$41.78 \%$ females (178), respectively. Most of the sample were from 11th grade accounting with $57.75 \%$, and the remaining $42.25 \%$ was from 12 th grade. With regard to this, $35.54 \%$ belonged to humanities, followed by $31.69 \%$ from commerce and $32.86 \%$ from the science stream (table 1). According to IAT score, the positive rate of excessive internet use among school students found in this study was $1.41 \%$, while the median and quartile range were 35 and 19-53, respectively (table 2 ).

Out of six excessive users of internet, four students were male and two were female. In addition, this study found that excessive use of internet was associated with the stream of students they chose. There was no excessive user that belonged to the science stream $(0 \%)$ as compared with both commerce $(50 \%)$ and humanities $(50 \%)$. However, the overall findings estimated that moderate users were higher in the commerce stream, at $44.44 \%$ (60 out of 135), as compared with humanities, at $27.15 \%$ (41 out of 151), and science stream, at $20 \%$ (28 out of 140), respectively. Normal users were higher in science, with $54.29 \%$ ( 76 out of 140 ), followed by $49.01 \%$ (74 out of 151) in humanities and 28.89\% (39 out of 135) in commerce, respectively.

This study found that excessive internet use had both negative impact on student lives, including emotional, conduct, hyperactivity and peer problems, as well as positive impact, such as prosocial behaviour. The mean values(SD) of emotional, conduct, hyperactivity, peer problems, prosocial and Total Difficulty Score (TDS) were 3.87 (2.28), 2.98 (1.7), 4.15 (1.97), 2.95 (1.73), 8.02 (1.7) and 13.95 (5.04), respectively, in students of 11th and 12th grade. The mean IA total score in this study was 36.63 (20.78), which indicated a mild level of IA among the 426 students. Out of the six excessive internet users, four students had emotional, one student had conduct, three had hyperactivity, three had peer problems and five had high score on prosocial. It signified that in the current study excessive use of internet had negative impact on students' lives, with a higher score on TDS compared with prosocial mean score $\left(p<0.0001, \chi^{2}=56.119\right)$. Hence, students who had problems caused by internet use were more likely to be classified as excessive internet users than students who did not have problems. However, this study found that behaviours such as emotional, conduct, hyperactivity, peer problems and prosocial were associated with excessive internet use (table 3 ).

Table 2 Prevalence of internet use with median and quartile range

\begin{tabular}{llcll}
\hline 19-53 IAT score & Frequency & Percentage & Median & Quartile range \\
\hline 0-30 (normal user) & 189 & 44.37 & 35 & $19-53$ \\
31-49 (mild user) & 102 & 23.94 & & \\
50-79 (moderate user) & 129 & 30.28 & & \\
80-100 (excessive user) & 6 & 1.41 & & \\
Total & 426 & 100.00 & & \\
\hline
\end{tabular}

IAT, Internet Addiction Test. 


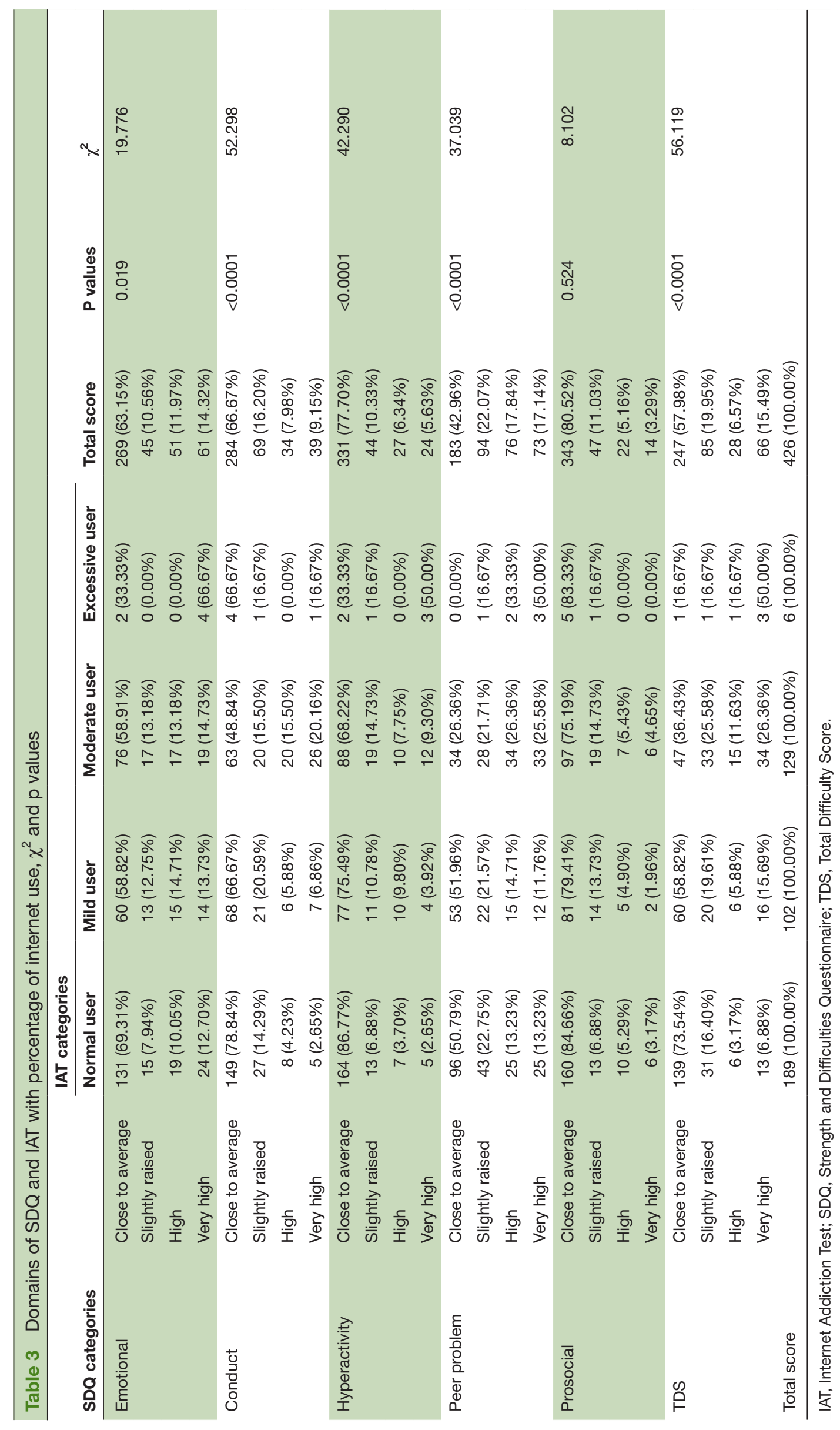


There was a significantly positive correlation between conduct, emotional, hyperactivity and peer problem domains of SDQ with the total IAT score, and there was a significantly negative correlation between prosocial domain of SDQ with the total IAT score. In addition, there was a significantly positive correlation between anticipation, excessive use, lack of control, neglect of social life, neglect of work and salience domains of IAT with conduct, hyperactivity and peer problem, while only three domains of IAT (i.e., excessive use, lack of control and salience, had significantly positive correlation with the emotional domain of SDQ. There was a significantly negative correlation between all domains of IAT and prosocial domain of SDQ. Furthermore, all the domains of IAT as well as the total IAT score positively correlated with TDS $(p<0.001)$ (table 4$)$. Comparison of IAT categories with TDS day was also found to be significant $(p<0.0001)$ (table 5).

\section{DISCUSSION}

\section{Main findings}

The positive rate of excessive internet use among school students found in this study was $1.41 \%$, which was closely related to some other studies done on student internet use worldwide, such as $1 \%$ in Greece $^{7}$ and $4.6 \%$ in Australia. ${ }^{22}$ The only published study from India, which evaluated IA using the Davis Online Cognition Scale in school-going children aged 16-18 years, reported a prevalence of $18 \%$. In the study of Goel and colleagues ${ }^{23}$ (using Young's original criteria), $74.5 \%$ of internet users were moderate users, $24.8 \%$ were possible addicts and $0.7 \%$ were addicts. In the study of Sharma and colleagues ${ }^{24}$ (IAT scoring), $57.3 \%$ were normal users, $35.0 \%$ were mild, $7.4 \%$ were moderate and $0.3 \%$ were severely addicted to the internet, while a low rate of IA was expected due to the still limited access most Indian students had to the internet compared with Western countries, and differences in cultural and social traditions in India.

Participants who took part in the study comprised $58.22 \%$ males and $41.78 \%$ females; the mean IAT score in males was $40.43(\mathrm{SD}=20.2)$ and the mean IAT score in females was $31.33(\mathrm{SD}=20.46)$. The $\mathrm{p}$ value was $<0.001$, which was statistically significant. It implies there is difference in the IAT scores across both genders. Some researchers have found that male internet users were more prone to excessive internet use. ${ }^{25-27}$ In contrast Young $(1996)^{28}$ stated that women were more subjected to excessive internet use than men. However, Brenner ${ }^{29}$ found no gender differences in relation to IA. Few Indian studies also suggested that males were more prone to excessive internet use than females (Grover et al, 2010), ${ }^{30}$ and Goel and colleagues ${ }^{23}$ reported that males in comparison with females were significantly more likely to be addicted $\left(\chi^{2}=10.2, p=0.006\right)$. This study supports the general literature that males tend to be more subjected to excessive internet use. It may be due to greater availability of internet-associated devices, time and money to males as compared with females in the Indian society.

In addition, this study found that IA was associated with the stream of students they chose. Excessive internet users were more in commerce and humanities as compared with science, and majority of science students were normal users as it may be due to more study materials in their curriculum and number of competitive exams they had to take, hence these students had less free time to spend on the internet.

In the current study, excessive use of internet had negative impact on students' lives as shown by a higher score on TDS (mean=13.95, $\mathrm{SD}=5.04$ ), which was higher compared with the prosocial mean score. Hence, students who had problems caused by internet use were more likely to be classified as excessive internet users than students who did not have problems. Most of the findings from this study are consistent with the literature. However, this study found that behaviours such as emotional, conduct, hyperactivity, peer problems and prosocial were associated with excessive internet use. These behaviours have not previously been identified as predictors of IA in the Indian literature. But one study conducted in secondary school students in Thailand reported that IA had been associated with both positive and negative impacts, including improving relationships between friends and family as positive impact, and low academic achievement, health, personal relationships problems and social problems as negative impact. ${ }^{31}$ Thus, more research needs to be done to explore it in greater detail and to what degree specific internet activities may influence the development of IA and the associated behaviours. The potential negative impact of internet use on students' lives should be considered more seriously. Although excessive internet use rate was only $1.41 \%$ among senior secondary school students, they were classified as excessive internet users and reported having difficulties in their emotional, conduct, hyperactivity and peer problem behaviours. Similarly, student respondents reported having emotional problems, such as frequent complaints of headache, worrying a lot, remaining unhappy and being downhearted, and becoming nervous in new situations. Students also reported having symptoms of peer problems, such as usually remaining alone, having few friends and generally being bullied by others. These problems, as discussed above, should be considered together with the total IA score when classifying internet addictive behaviours.

\section{Limitations}

1. The sample size was small. Larger sample size could add power to the study.

2. We are not able to assess the short-term and long-term impact of internet use on students.

3. Several other factors like economic condition, family relation, time spent on internet and accessibility of internet also have huge impact on IA, which should be incorporated in future research. 


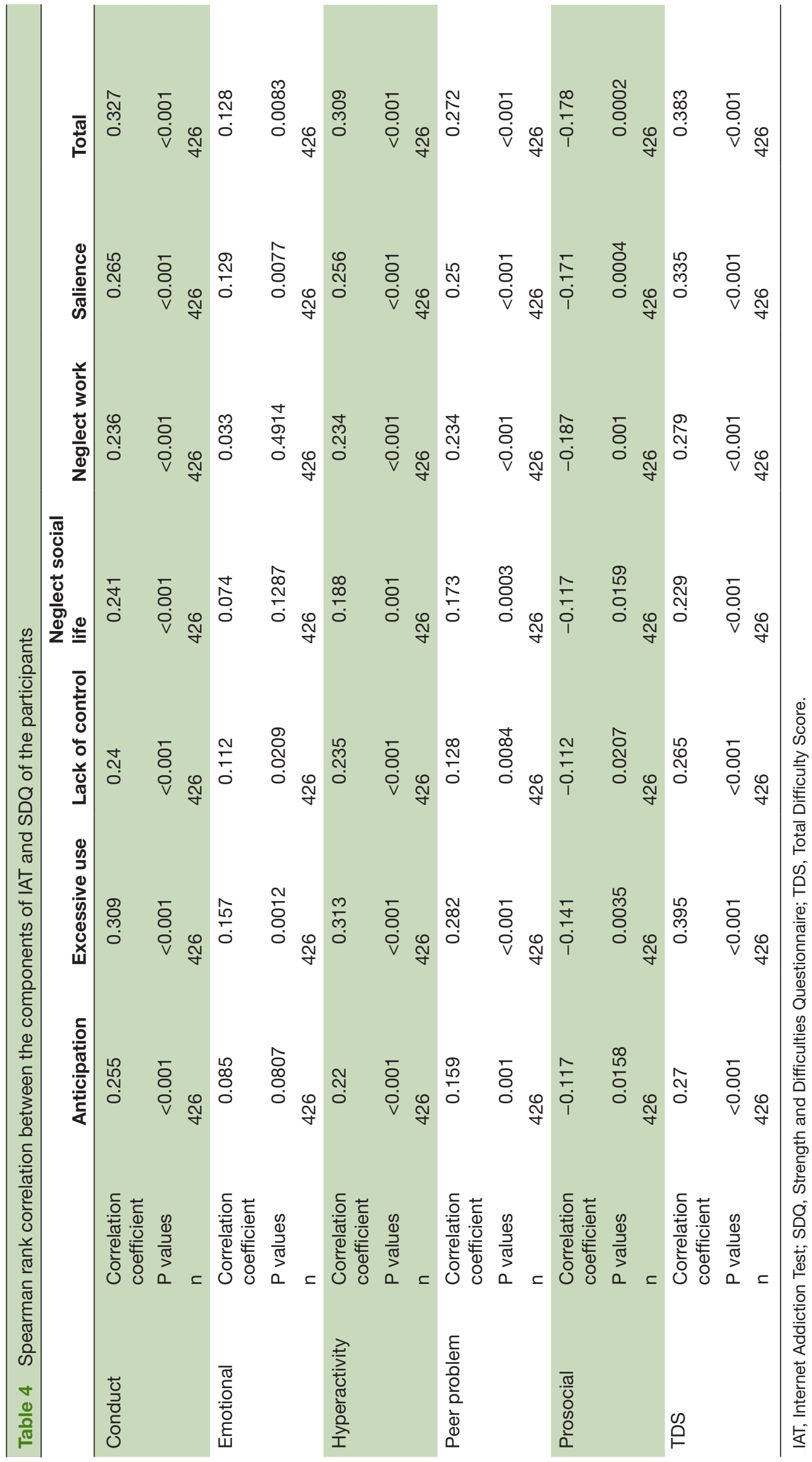


Table 5 Comparison between TDS and IAT categories

\begin{tabular}{llllll}
\hline IAT categories & Normal user & Mild user & Moderate user & Excessive user & P values \\
\hline TDS & $12(9-15)$ & $13(11-17)$ & $16(13-19)$ & $22(16-26)$ & $<0.0001$ \\
Total IAT score & $17(10-25)$ & $40(35-45)$ & $59(54-65)$ & $85(83-90)$ & $<0.0001$ \\
\hline
\end{tabular}

IAT, Internet Addiction Test; TDS, Total Difficulty Score.

\section{Implications}

Excessive internet use causes negative consequences to users, such as emotional, conduct, hyperactivity and peer problem behaviours. These problems should be considered together with excessive internet use when classifying internet addictive behaviours. To avoid negative consequences, we should promote education about responsible use and supervision of students by family members, so that problem should be identified by addictive users themselves.

Contributors AK and MK helped in the analysis of data, proof-reading and result formation. PT helped in the data collection and compilation of analysis. SKM helped in the manuscript preparation. SND provided valuable guidance and input to complete the task on time.

Funding The authors have not declared a specific grant for this research from any funding agency in the public, commercial or not-for-profit sectors.

Competing interests None declared.

Patient consent for publication Not required.

Ethics approval Ethical clearance was taken from the Institutional Ethics Committee, PGIMER, RML Hospital, New Delhi on 27 September 2016.

Provenance and peer review Not commissioned; externally peer reviewed. Data sharing statement № additional data are available.

Open access This is an open access article distributed in accordance with the Creative Commons Attribution Non Commercial (CC BY-NC 4.0) license, which permits others to distribute, remix, adapt, build upon this work non-commercially, and license their derivative works on different terms, provided the original work is properly cited and the use is non-commercial. See: http://creativecommons.org/ licenses/by-nc/4.0

Author note The authors express their sincere regards to Dr Subodh Kumar Mahto (Senior Resident, Department of Medicine, PGIMER and Dr RML Hospital, New Delhi) for his time and immense help in making the draft. The authors would also like to thank Parul Tanwar (MBBS final year, VMMC and SJH, New Delhi) for data collection and analysis.

\section{REFERENCES}

1. Internet world stats [Internet], 2018. Miniwatts marketing group. Available: https://www.internetworldstats.com/stats.htm

2. Goldberg I, 1996. Internet addiction. Available: http://web.urz. uniheidelberg.de/Netzdienste/anleitung/wwwtips/8/addict.html [Accessed 22 Mar 2010].

3. Davis RA. A cognitive behavioral model of pathological internet use (PIU) Comput hum Behav 2001;17:187-95.

4. Young KS. Internet addiction: the emergence of a new clinical disorder Cyberpsychol Behav 1998;3:237-44.

5. Shaw M, Black DW. Internet addiction: definition, assessment, epidemiology and clinical management. CNS Drugs 2008;22:353-65.

6. Tao R, Huang X, Wang J, et al. Proposed diagnostic criteria for Internet addiction. 2010;105:556-64.

7. Tsitsika A, Critselis E, Kormas G, et al. Internet use and misuse: a multivariate regression analysis of the predictive factors of internet use among Greek adolescents. Eur J Pediatr 2009;168:655-65.

8. Milani L, Osualdella D, Di Blasio P. Quality of interpersonal relationships and problematic internet use in adolescence. Cyberpsychol Behav 2009;12:681-4.
9. Kandell JJ. Internet addiction on campus: the vulnerability of college students. Cyberpsychol Behav 1998:1:11-17.

10. Young J. Common comorbidities seen in adolescents with attention-deficit/hyperactivity disorder. Adolesc Med State Art Rev 2008:19:216-28.

11. Ko CH, Yen JY, Chen CS, et al. Psychiatric comorbidity of Internet addiction in college students: an interview study. CNS Spectr 2008;13:147-53.

12. Black DW, Belsare G, Schlosser S. Clinical features, psychiatric comorbidity, and health-related quality of life in persons reporting compulsive computer use behavior. J Clin Psychiatry 1999;60:839-44.

13. Armstrong L, Phillips JG, Saling LL. Potential determinants of heavier Internet usage. Int J Hum Comput Stud 2000;53:537-50.

14. Chak K, Leung L. Shyness and locus of control as predictors of Internet addiction and internet use. Cyberpsychol Behav 2004;7:559-70.

15. Caplan SE, loneliness Ramong. Social anxiety, and problematic internet use. Cyberpsychol Behav 2007;10:234-42.

16. Kim K, Ryu E, Chon MY, et al. Internet addiction in Korean adolescents and its relation to depression and suicidal ideation: a questionnaire survey. Int J Nurs Stud 2006;43:185-92.

17. Mathy RM, Cooper A. The duration and frequency of internet use in a nonclinical sample: suicidality, behavioral problems, and treatment histories. Psychotherapy 2003;40:125-35.

18. American Psychiatric Association. Diagnostic and statistical manual of mental disorders. 796. 5th ed. Arlington, VA: American Psychiatric Publishing, 2013.

19. Usman NH, Alavi M, Shafeq SM. Relationship between Internet addiction and academic performance among foreign undergraduate students. Procedia - Social and Behavioral Sciences 2014:114:845-51.

20. Kaya F, Delen E, Young KS. Psychometric properties of the Internet addiction test in Turkish. J Behav Addict 2016;5:130-4.

21. Goodman R, Ford T, Simmons $\mathrm{H}$, et al. Using the strengths and difficulties questionnaire (SDQ) to screen for child psychiatric disorders in a community sample. Br J Psychiatry 2000;177:534-9.

22. Thomas N, Martin FH. Video-arcade game, computer game and Internet activities of Australian students: participation habits and prevalence of addiction. Aust J Psychol 2010;62:59-66.

23. Goel D, Subramanyam A, Kamath R. A study on the prevalence of Internet addiction and its association with psychopathology in Indian adolescents. Indian J Psychiatry 2013;55:140-3.

24. Sharma A, Sahu R, Kasar P, et al. Internet addiction among professional courses students: a study from central India. Int J Med Sci Public Health 2014;3:1069.

25. Morahan-Martin J, Schumacher P. Incidence and correlates of pathological internet use among college students. Computers in Human Behavior 2000;16:13-29.

26. Scherer K. College life on-line: Healthy and unhealthy internet use. $J$ Coll Stud Dev 1997;38:655-65.

27. Chou C, Hsiao M-C. Internet addiction, usage, gratification, and pleasure experience: the Taiwan college students' case. Comput Educ 2000;35:65-80.

28. YOUNG KS. Internet addiction: the emergence of a new clinical disorder. CyberPsychology \& Behavior 1998;1:237-44.

29. Brenner V. Psychology of computer use: XLVII. Parameters of internet use, abuse and addiction: the first 90 days of the Internet usage survey. Psychological Reports 1997;80:879-82.

30 Grover S, Chakraborty K, Basu D. Pattern of internet use among professionals in India: critical look at a surprising survey result. Ind Psychiatry J 2010;19:94-100.

31. Wanajak K. Internet use and its impact on secondary school students in Chiang Mai. Thailand: Edith Cowan University Research Online, 2011. 
Dr. Nitin Kumar graduated with a bachelor's degree from the Vardhman Mahavir Medical College EO Safdarjung Hospital in 2016. He is currently studying for a master's degree at the Postgraduate Institute of Medical Education and Research (PGIMER) Dr. RML Hospital, New Delhi, Delhi, India. His research interest includes substance use disorder and internet addiction. 